\title{
A correspondência do Fundo Aracy de Carvalho Guimarães Rosa ${ }^{1}$
}

Daniel Reizinger Bonomo ${ }^{2}$

Resumo

O texto relata nossa experiência de organização da Série Correspondência do Fundo Aracy de Carvalho Guimarães Rosa, pertencente ao Instituto de Estudos Brasileiros da USP, entre os meses de agosto de 2005 e junho de 2006. O artigo descreve o processo através do qual os documentos foram arranjados, além de apresentar algo de seu conteúdo.

Palavras-chave

Organização de acervos pessoais, correspondência, Aracy de Carvalho Guimarães Rosa, João Guimarães Rosa.

1 O texto relata um trabalho realizado dentro do projeto Conservação preventiva de correspondências e partituras dos acervos: Caio Prado Jr., Camargo Guarnieri, Fernando de Azevedo, Graciliano Ramos, João e Aracy Guimarães Rosa, que recebeu apoio financeiro da VITAE.

2 Mestre em Língua e Literatura Alemã pela Universidade de São Paulo. São Paulo, Brasil. E-mail: drbonomo@gmail.com 


\section{The correspondence of Aracy de Carvalho Guimarães Rosa's Archive}

Daniel Reizinger Bonomo

Abstract

The text refers to our experience, between August 2005 and June 2006, in organizing the correspondence which belongs to Aracy de Carvalho Guimarães Rosa's Archive, owned by the Instituto de Estudos Brasileiros of USP. The article describes the process in which the documents were arranged, and presents some of the correspondence contents.

Keywords

Organization of personal archives, correspondence, Aracy de Carvalho Guimarães Rosa, João Guimarães Rosa. 
Doado ao Instituto de Estudos Brasileiros da Universidade de São Paulo em fevereiro de 2004, o Fundo Aracy de Carvalho Guimarães Rosa compõe-se de ampla variedade de manuscritos, correspondência, diários e agendas, bem como materiais impressos, entre recortes de jornais e revistas, fotografias e livros - documentação que, em boa parte, refere-se também à vida e obra do escritor João Guimarães Rosa.

Aracy de Carvalho Guimarães Rosa, nascida Aracy Moebius de Carvalho, em 20 de abril de 1908 na cidade de Rio Negro, Paraná, conheceu João Guimarães Rosa na Alemanha em 1938, período em que ambos trabalharam na repartição consular brasileira de Hamburgo. É conhecida dos leitores a dedicatória que se encontra nas primeiras páginas de toda edição do Grande sertão: veredas, e que vale não só como testemunho da importância de Aracy para o escritor, mas também como registro de que eram dela os direitos autorais do romance:

A

Aracy, minha mulher, Ara, pertence este livro. ${ }^{3}$

Aracy fora primeiro casada com Johannes Tess, com quem teve em 1929 seu único filho, Eduardo Tess. Já desquitada, uniu-se a João Guimarães Rosa, fazendo-lhe companhia até sua morte, em 1967. Juntos, durante a conflituosa época da Alemanha de Hitler, prestaram assistência a judeus perseguidos pelo nazismo ao facilitarem-lhes a fuga com a obtenção de vistos. Por suas ações humanitárias, Aracy de Carvalho Guimarães Rosa foi diversas vezes homenageada, incluindo o registro de seu nome no Memorial do Holocausto, inaugurado em Washington, em 1993.

Os documentos do Fundo Aracy de Carvalho Guimarães Rosa cobrem um significativo período histórico, além de ser precioso contributo ao Fundo João Guimarães Rosa, também pertencente ao IEB. A primeira equipe a trabalhar com o fundo, formada por Maria Neuma Barreto Cavalcante (coordenadora), Lenira Marques Covizzi e Mônica Gama, realizou um inventário em que se listavam sumariamente os documentos doados. A nossa equipe, composta por Daniel Bonomo (coordenador), Elisandra de Souza Pedro, Klaus Wernet e Thais Biazioli de Oliveira, iniciou o seu trabalho em agosto de 2005. Assumimos en-

3 ROSA, João Guimarães. Grande sertão: veredas. $2^{\text {a }}$ ed. Rio de Janeiro: José Olympio, 1958. p. 3. Pode-se conferir a importância desta dedicatória para João Guimarães Rosa em suas cartas de 19 de junho de 1964 e de 25 de junho de 1964 para seu tradutor alemão Curt Meyer-Clason. Cf. ROSA, João Guimarães. Correspondência com seu tradutor alemão Curt Meyer-Clason (1958-1967). Rio de Janeiro: Nova Fronteira; Academia Brasileira de Letras; Belo Horizonte: Ed. da UFMG, 2003. p. 185-188. 
tão a organização da correspondência do acervo de Aracy de Carvalho Guimarães Rosa, encerrando-a em junho de 2006. Nosso trabalho fez parte de um projeto do serviço de conservação e restauro e do corpo acadêmico do IEB intitulado Conservação preventiva de correspondências e partituras dos acervos: Caio Prado Jr., Camargo Guarnieri, Fernando de Azevedo, Graciliano Ramos, João e Aracy Guimarães Rosa, cujo financiamento foi concedido pela VITAE. Pretendemos, em nosso texto, relatar a experiência da organização dos documentos que compõem a Série Correspondência deste acervo, bem como apresentar aos possíveis interessados um pouco daquilo com que deparamos ao longo do nosso trabalho.

"Estou desempacotando minha biblioteca. Sim, estou. Os livros, portanto, ainda não estão nas estantes; o suave tédio da ordem ainda não os envolve". Com esta formulação, Walter Benjamin inicia um de seus escritos sobre a figura do colecionador, tema de seu interesse, e que ele mesmo protagoniza ${ }^{4}$. Benjamin privilegia em seu texto o ato de colecionar em suas relações com o caos de lembranças por ele despertado, trazendo à memória situações animadas a partir de um contato mais demorado de um colecionador de livros - no caso, ele próprio com cada um de seus exemplares. Destino e acaso são também seus temas, e a história muito própria que envolve cada objeto de uma coleção corre um menor risco de se perder caso aquele que o possui e organiza, como colecionador, estiver por perto. Contudo, perguntamos, e no caso de uma coleção pública em que não há mais a presença deste colecionador, habitando uma instituição? Benjamin soube reconhecer o "lado social" das coleções públicas, mas não encontrou maior interesse nelas. Fora de um registro afetivo, os objetos de uma coleção pública têm necessidades de outra ordem, quer dizer, pedem algo mais objetivo, visando facilitar caminhos para um provável consulente.

Encontramos o acervo de Aracy de Carvalho Guimarães Rosa acondicionado e dividido em 25 caixas, sem que houvesse nessa separação dos documentos alguma ordem que já indicasse os rumos de uma organização tal como desejávamos. Tínhamos à mão apenas a já referida listagem, pouco detalhada, do conteúdo de cada uma das caixas, revelando que enfrentaríamos em cada um desses conjuntos unidades complexas de amontoados de papéis de enorme pluralidade. Por exemplo, numa única caixa encontramos cartas, telegramas e cartões-postais entre documentos manuscritos de feição diversa, com

4 BENJAMIN, Walter. Desempacotando minha biblioteca - um discurso sobre o colecionador. In: . Rua de mão única: Obras escolhidas II. $5^{\mathrm{a}}$ ed. São Paulo: Brasiliense, 2000. p. 227-235. 
anotações de toda espécie, além de recibos e listas de compras do casal Guimarães Rosa, bulas de medicamentos, lembranças de viagens etc. O primeiro passo de nosso trabalho foi, portanto, o estudo desses documentos com o propósito de separar o material que deveria integrar a Série Correspondência. Orientados pelo corpo técnico e acadêmico do IEB e atentos à disposição dos documentos, procuramos não dissolver unidades de conjuntos de documentos que se apresentavam. Cartas, cartões-postais, telegramas e bilhetes foram separados do restante do material do acervo e deram início à Série Correspondência.

Selecionados os documentos que interessavam à nossa organização, três particularidades deste acervo saltaram diante de nós: a primeira foi uma significativa quantidade de documentos de terceiros, indicando que, ao receber o acervo pessoal de Aracy de Carvalho Guimarães Rosa, o IEB acolheu documentos de boa parte de sua família; a segunda foi o também expressivo montante de cartões-postais, que formam uma bela coleção; e a terceira foi a não menor soma de documentos em língua alemã. Por conseguinte, decidimos que os cartõespostais deveriam receber um acondicionamento específico, apartados do restante dos documentos. Decidimos também que o conteúdo dos documentos em língua alemã deveria ganhar um resumo em língua portuguesa, facilitando a consulta por um maior número de pessoas.

Durante o desenvolvimento deste trabalho, momento em que líamos toda a correspondência, surgiram dificuldades sobretudo no reconhecimento de remetentes e destinatários e no trato com os manuscritos, muita vez ilegíveis, em língua alemã. À proporção que adquiríamos alguma intimidade com o material, identificávamos os autores deste conjunto de documentos e com menor dificuldade podíamos decifrar nas suas cartas conteúdos menos obscuros. Os documentos que se nos apresentaram não despertavam em nós, como fariam provavelmente com algum membro da família de Aracy, lembranças que, num certo sentido, pudessem orientar sua organização. No entanto, a distância que nos separava daquele material poderia também contribuir, com todos seus riscos, para certa objetividade que procurávamos obter em sua ordenação. Pouco a pouco, conhecemos a história familiar de Aracy, da vida de sua mãe Sida Moebius de Carvalho e de sua tia Lucy Luttmer signatárias de um número grande de cartas -, e das relações de outros tantos amigos inicialmente desconhecidos. Foi assim que, assumindo, em colaboração com o corpo técnico do IEB, decisões que nos pareceram as mais adequadas, dividimos a correspondência de Aracy em 21 novas caixas, sendo 17 para cartas, telegramas, cartões e bilhetes, 
e cinco especialmente confeccionadas para os cartões-postais. Segue abaixo a relação das caixas tal como se encontram organizadas:

\section{Descrição do conteúdo das caixas da Série Correspondência:}

\section{Correspondência de Aracy de Carvalho Guimarães Rosa:}

Caixa 01: Correspondência entre Aracy de Carvalho Guimarães Rosa e Sida Moebius de Carvalho. De 25 de maio de 1924 a 30 de dezembro de 1949. 111 documentos.

Caixa 02: Correspondência entre Aracy de Carvalho Guimarães Rosa e Sida Moebius de Carvalho. De 06 de janeiro de 1950 a 22 de julho de 1987. 157 documentos.

Caixa 03: Correspondência entre Aracy de Carvalho Guimarães Rosa e diversos correspondentes I (grupos: Mario Calábria, Arthur Gouvêia Portella, Lili e Américo Pimentel e Antônio Campos Jr.). De 11 de março de 1925 a 14 de julho de 1985. 94 documentos.

Caixa 04: Correspondência entre Aracy de Carvalho Guimarães Rosa e diversos correspondentes II. De 13 de abril de 1920 a 03 de agosto de 1964. 120 documentos.

Caixa 05: Correspondência entre Aracy de Carvalho Guimarães Rosa e diversos correspondentes III. De 26 de maio de 1966 a dezembro de 1971. 148 documentos.

Caixa 06: Correspondência entre Aracy de Carvalho Guimarães Rosa e diversos correspondentes IV. De 22 de maio de 1972 a dezembro de 1982. 109 documentos.

Caixa 07: Correspondência entre Aracy de Carvalho Guimarães Rosa e diversos correspondentes V. De 01 de janeiro de 1983 a 20 de dezembro de 1989. 88 documentos.

Caixa 08: Correspondência entre Aracy de Carvalho Guimarães Rosa e diversos correspondentes VI. De 28 de janeiro de 1986 a 08 de março de 1994 (mais documentos não datados). 115 documentos.

\section{Correspondência de terceiros:}

Caixa 09: Correspondência entre Sida Moebius de Carvalho e diversos correspondentes I. De 14 de abril de 1909 a 22 de dezembro de 1939. 123 documentos.

Caixa 10: Correspondência entre Sida Moebius de Carvalho e diversos correspondentes II. De 18 de janeiro de 1940 a 15 de dezembro de 1952. 136 documentos. 
Caixa 11: Correspondência entre Sida Moebius de Carvalho e diversos correspondentes III. De 02 de janeiro de 1953 a 22 de julho de 1980 (mais documentos não datados). 121 documentos.

Caixa 12: Correspondência entre João Guimarães Rosa e diversos correspondentes. De 11 de junho de 1940 a 20 de janeiro de 1968. 187 documentos.

Caixa 13: Correspondência da família Luttmer/Correspondência entre Amadeu de Carvalho e diversos correspondentes. De 26 de julho de 1914 a 15 de julho de 1955. 159 documentos.

Caixa 14: Correspondência da família Tess (Ida, Hugo e Johannes Tess). De 12 de abril de 1902 a 08 de janeiro de 1971. 167 documentos.

Caixa 15: Correspondência entre Detlef Drenkmann e Annemarie Voss/Correspondência entre terceiros (diversos). De 14 de julho de 1912 a 18 de outubro de 1979. 126 documentos.

Caixa 16: Envelopes.

\section{Cartões-postais:}

Caixa 17: Correspondência entre Aracy de Carvalho Guimarães Rosa e Sida Moebius de Carvalho. De 27 de maio de 1924 a 18 de agosto de 1972. 118 cartões.

Caixa 18: Correspondência entre Aracy de Carvalho Guimarães Rosa e diversos correspondentes. De 22 de junho de 1924 a 27 de março de 1990 (mais documentos não datados). 296 cartões.

Caixa 19: Correspondência entre Sida Moebius de Carvalho e diversos correspondentes. De 1902 a 31 de dezembro de 1937. 175 cartões.

Caixa 20: Correspondência entre Sida Moebius de Carvalho e diversos correspondentes. De 01 de janeiro de 1938 a 08 de julho de 1971. 264 cartões.

Caixa 21: Correspondência de João Guimarães Rosa, Amadeu de Carvalho, da família Tess, da família Luttmer, de Ignácio da Silva, de Detlef Drenkmann e Annemarie Voss e outros. De 25 de novembro de 1904 a setembro de 1967. 256 cartões.

Não poderíamos deixar de mencionar neste relato o trabalho do serviço de conservação e restauro de documentos do IEB, compreendendo desde a fase de higienização dos documentos até a discussão de quais seriam os melhores materiais para o acondicionamento final da correspondência. As cartas foram, quando necessário, desdobradas e limpas com trincha de pêlos macios, recebendo também, em alguns ca- 
sos, pequenos reparos; já os cartões-postais, de material diverso, foram limpos com pó de borracha. Para o acondicionamento final das cartas foram confeccionadas 16 caixas com revestimento interno em Tyvek e externo em Percalux; e para os cartões-postais foram feitas cinco caixas envolvidas em Frankonia, nas quais se guardam suas imagens dentro de envelopes transparentes de Mylar-D. No interior das 16 caixas de cartas, os documentos foram envolvidos todos em envelopes de papel Filiset Neutro.

Atualmente, o consulente interessado pode conferir este trabalho ao visitar o arquivo do IEB. Para facilitar a consulta, o setor de informática do IEB desenvolveu um banco de dados que guarda as informações básicas de cada documento, tais como remetentes e destinatários das cartas, datas de envio, localidades, línguas em que foram escritos os textos etc. Nesse banco de dados há também resumos dos conteúdos dos documentos, facilitando ao pesquisador menos habituado com a língua alemã, por exemplo, adiantar-se em sua busca.

Finalmente, mencionemos em nosso texto algo daquilo que encontramos durante estes meses de trabalho. Já observamos que os documentos do Fundo Aracy de Carvalho Guimarães Rosa cobrem importantes momentos históricos. Citemos, por exemplo, um trecho de uma carta de Aracy para sua amiga Lili Pimentel, em 20 de novembro de 1939, início da Segunda Guerra Mundial:

Já no terceiro mês de guerra, a Senhora não póde imaginar como isto aqui está, e que vida estamos levando. Os víveres só podem ser comprados em quantidade limitadas, por meio de cartas, o mesmo acontecendo para a acquisição de quasi tudo a gente precisa de apresentar nas lojas "Bezugsschein” especial. Meias, só se podem comprar 4 pares por ano; vestidos de lã, um. E assim por deante. Felizmente, nós do Consulado recebemos cartas especiais, que nos dão direito a ter a quantidade de coisas de que precisamos, a não ser gazolina e sabão, artigos estes que são contingentados mais rigorosamente, e para os quais taxaram a quantidade que podemos obter. Por enquanto é esta a nossa situação, que temos muito receio de ver, a qualquer hora, peorar. ${ }^{5}$

Observamos antes também que a coleção de cartões-postais deste acervo impressiona. Entre os mais interessantes, poderíamos destacar um curioso grupo de 18 cartões não assinados e endereçados ao "Ilustríssimo Senhor Embaixador" ou ao "Señor Don Embajador" ou então somente ao "Embaixador” João Guimarães Rosa. Todos esses

5 Foi mantida a grafia original, sem que se fizessem quaisquer correções sobre o texto. 
cartões contêm frases que, imediatamente, reconhecemos pertencer à sua ficção. Chegamos a supor, orientados por uma proximidade entre a grafia dessas frases e os manuscritos do escritor, que se tratavam de cartões escritos pelo próprio João Guimarães Rosa. Sem mais evidências, pois que não encontramos documentos que comprovassem tais viagens em seus últimos anos de vida - os cartões são, na sua maioria, do ano de 1966 -, assim como não procedemos a um exame comparativo mais rigoroso, a autoria desses cartões permaneceu sem identificação. Entendendo, contudo, que este conjunto de imagens associadas a trechos literários funciona como uma espécie de ilustração do texto de João Guimarães Rosa, empreendemos uma busca a fim de identificar tais frases em sua obra. Dos 18 cartões encontrados, conseguimos localizar as frases de 17 deles. Relacionamos, a seguir, esses cartõespostais, com a transcrição das frases em questão, a que acrescentamos a menção ao texto ficcional em que elas figuram:

\section{Cartões-postais para João Guimarães Rosa:}

Imagem do cartão-postal: Ponte Hercílio Luz em Florianópolis. Data: 04 de junho de 1965. Texto: "Ia dar luar, o para caminhada, do homem e da onça, erradios, na mata do Gorutuba". Texto ficcional em que a frase se encontra: No prosseguir, de Tutaméia.

Imagem do cartão-postal: Umbu Hotel, em Porto Alegre. Data: 11 de junho de 1965. Texto: "Mudo modo - como quando a onça pirraça". Texto ficcional em que a frase se encontra: No prosseguir, de Tutaméia.

Imagem do cartão-postal: Navio Giulio Cesare. Data: 26 de agosto de 1966. Texto: "Senão quando o vapor apitou e se avistou subindo o rio". Texto ficcional em que a frase se encontra: Estoriinha, de Tutaméia.

Imagem do cartão-postal: Torre do Arcebispo em Tarragona. Data: 26 de agosto de 1966. Texto: "Revenho ver; a casa, esta, em fama e idéia. Só por fora, com efeito". Texto ficcional em que a frase se encontra: Curtamão, de Tutaméia.

Imagem do cartão-postal: Estanque del Retiro em Madri. Data: setembro de 1966. Texto: "Retrato de Cavalo". Título de conto: Retrato de cavalo, de Tutaméia.

Imagem do cartão-postal: Retrato de um imperador mítico da Dinastia Ming (1368-1644). Data: 30 de setembro de 1966. Texto: “- Mai, ocê é o chim? - Sou sim, o chim sou”. Texto ficcional em que a frase se encontra: Orientação, de Tutaméia. 
Imagem do cartão-postal: Rosas. Data: 30 de setembro de 1966. Texto: "A flor é só flor". Texto ficcional em que a frase se encontra: Arroio-das-antas, de Tutaméia.

Imagem do cartão-postal: Desenho de um casal dançando. Data: 30 de setembro de 1966. Texto: "Ímpar o par". Texto ficcional em que a frase se encontra: Reminisção, de Tutaméia.

Imagem do cartão-postal: Gato sobre uma bacia de peixes, de Koryusai.

Data: 30 de setembro de 1966. Texto: "QUEMADMODUM. E é um gato”. Título e início de conto: Quemadmodum, de Ave, palavra.

Imagem do cartão-postal: Lingüiça com cebolas. Data: 30 de setembro de 1966. Texto: "Dói, dor". Texto ficcional em que a frase se encontra: O porco e seu espírito, de Ave, Palavra.

Imagem do cartão postal: Monumento a Felipe IV em Madri. Data: 06 de novembro de 1966. Texto: "Retrato de Cavalo". Título de conto: Retrato de cavalo, de Tutaméia.

Imagem do cartão-postal: Rio Manzanares. Data: 06 de novembro de 1966. Texto: "Rio meu de amor é o Urucuia, onde tanto boi berra”. Texto ficcional em que a frase se encontra: Grande sertão: veredas. Une-se aqui, em uma frase, dois trechos do Grande sertão: veredas: "O senhor vá. Alguma coisa, ainda encontra. Vaqueiros? Ao antes - a um, ao Chapadão do Urucuia - aonde tanto boi berra..." (p. 31 da edição citada na nota 3 deste texto), e: "Rio meu de amor é o Urucuia" (p. 71).

Imagem do cartão-postal: Catedral de Toledo. Data: 14 de novembro de 1966. Texto: "Sacristão mais maçon do alto espiavam". Texto ficcional em que a frase se encontra: Umas formas, de Tutaméia.

Imagem do cartão-postal: Monumento a Cervantes em Madri. Data: 1966. Texto: "Ímpar o par". Texto ficcional em que a frase se encontra: Reminisção, de Tutaméia.

Imagem do cartão-postal: Interior da Capela de São Jorge. Data: 1966. Texto: "Sacristão mais maçon do alto espiavam". Texto ficcional em que a frase se encontra: Umas formas, de Tutaméia.

Imagem do cartão-postal: Costa Dorada. Data: 1966. Texto: "Senão quando o vapor apitou se avistou subindo o rio, aportava da Bahia cheio de pessoas." Texto ficcional em que a frase se encontra: Estoriinha, de Tutaméia.

Imagem do cartão-postal: Costa que vai de Cadaqués ao Cabo de Creus. Data: 24 de março de 1967. Texto: "Amb tot l'afecte i apreci que sento al recordalo. Ao revê-lo... Iô Wi”. Referência ao conto Retrato de cavalo, de Tutaméia. 
Imagem do cartão-postal: Vista noturna da avenida Goiás, em Goiânia. Sem data. Texto: "Do jeito que a rosa floresce no jardim, você é bonita no meu coração...” Não encontramos esse texto na obra de João Guimarães Rosa.

Entre os documentos da Série Correspondência do Fundo Aracy de Carvalho Guimarães Rosa o pesquisador interessado deve ainda muito encontrar. Não apenas os estudiosos de João Guimarães Rosa, que certamente apreciarão visitar a caixa de suas cartas, mas também pesquisadores em geral. Estes poderão aqui e ali revelar o valor histórico deste conjunto de cartas e imagens, desdobrando, assim, aquilo que iniciamos.

Encerra-se, portanto, uma etapa importante da organização do Fundo Aracy de Carvalho Guimarães Rosa. Porém, ainda há no acervo mais documentos a ser ordenados. A Série Correspondência, em nossa organização, totalizou cerca de 3070 documentos, deixando ainda muito por fazer. A organização de um acervo não se esgota assim, quer dizer, documentos ainda poderão aparecer e a disposição que demos ao material não está livre de equívocos. Igualmente, novos trabalhos contribuem para o entendimento deste inicial. É que, entre os meses de outubro de 2007 e abril de 2008, organizamos (desta vez somente ao lado de Ricardo T. R. de Melo, e sob nossa coordenação) dois outros acervos: o Acervo Nonada Cultural Ltda., composto de documentos relacionados aos direitos autorais dos herdeiros de Grande Sertão: veredas, apresentando, ainda, uma considerável coleção de recortes de imprensa sobre o escritor, complementar, em muitos sentidos, à coleção de mesma natureza do Fundo João Guimarães Rosa, do IEB; e o Acervo Família Tess, composto de grande quantidade de fotografias da família de Aracy e de João Guimarães Rosa, além de outros documentos diversos, como, por exemplo, um significativo conjunto de cartas trocadas entre o escritor e seus editores no exterior.

Vencido este percurso inicial, esperamos que o trabalho no acervo desta mulher que completou, em 2008, um centenário, tenha continuidade e possa, ainda mais, prestar-se ao interesse de um público que, como sabemos, encontrará em seus documentos mais do que nós.

Recebido em 15 de setembro de 2007

Aprovado em 30 de janeiro de 2009 